\title{
ASO Author Reflections: SPIO, a New Sentinel Node Tracer with Interesting Future Clinical Applications
}

\author{
Fredrik Wärnberg, MD, and Andreas Karakatsanis, PhD, MD \\ Department of Surgical Sciences, Uppsala University, Uppsala, Sweden
}

\section{PAST}

Superparamagnetic iron oxide nanoparticles (SPIO) is a new tracer for sentinel node (SN) detection with comparable results to dual technique, Technetium ${ }^{99} \pm$ blue dye. ${ }^{1}$ SPIO has not been associated with allergic reactions, and nuclear medicine facilities are not required. Concerns have however been raised regarding artifacts on magnetic resonance imaging (MRI) and brownish skin staining.

At Uppsala University Hospital, SPIO has routinely been used for 3 years. It has simplified planning for surgery, partly due to the possibility of injecting SPIO up to 4 weeks before surgery. ${ }^{2}$ To avoid skin staining, our injection technique was modified and SPIO is now injected close to the tumor instead of behind the areola as in earlier studies. Blue dye also results in skin staining, but little is reported on the cosmetic outcome. Here, women were asked $^{3}$ about their experience of SPIO staining in relation to different injection techniques, and the SN detection rate was recorded.
This ASO Author Reflections is a brief invited commentary on the article "Long-Term Outcome after Retroareolar versus Peritumoral Injection of Superparamagnetic Iron Oxide Nanoparticles (SPIO) for Sentinel Lymph Node Detection in Breast Cancer Surgery," Ann Surg Oncol. 2019; 26:1247-1253.

(C) The Author(s) 2019

First Received: 20 May 2019; Published Online: 17 June 2019

F. Wärnberg, MD

e-mail: fredrik.warnberg@akademiska.se

\section{PRESENT}

SPIO was injected in different ways and at different time points. Peritumoral, in comparison with retroareolar injection, resulted in less skin staining with comparable sentinel node detection rates. Most women did not consider skin staining a cosmetic problem. Three years after peritumoral injection, $9.4 \%$ had a residual stain, but it was regarded as "no" or "a minor cosmetic problem" by $88 \%$ of the women. The staining faded and the size diminished successively over time. The volume of SPIO used was $2 \mathrm{ml}$, diluted in $3 \mathrm{ml} \mathrm{NaCl}$ or local anesthetic. We expect that staining could be decreased further by using smaller volumes of nondiluted SPIO, as we have promising results in an ongoing study.

Using different injection sites resulted in similar SN detection rates. However, injecting the SPIO before the day of surgery increased the SN detection rate by about $4 \%$ (98.0\% vs. $94.2 \%, p=0.06$ ), with 0.3 more SNs retrieved. As we usually operate within 4 weeks, SPIO can be injected at the outpatient visit, when planning surgery.

\section{FUTURE}

SPIO has recently been Food and Drug Administration (FDA) approved, but only for mastectomy patients. However, we see several new possibilities. In ductal carcinoma in situ (DCIS) patients, SPIO is injected at primary surgery but SN biopsy (SNB) is not performed. In those upgraded to invasive cancer, SNB is performed at a second operation. This reduces unnecessary SNBs and saves money. ${ }^{4}$ The concept can be applied to prophylactic mastectomies.

The combination of SPIO and a magnetic seed for SN detection and tumor localization can simplify logistics further. SPIO and the seed are injected up to 4 weeks before surgery by the radiologist. ${ }^{5}$ 
Long-term MRI effects need to be studied, but by using a small peritumoral dose, most SPIO is removed at surgery and preliminary data show that artifacts are minimized.

Lastly, a SPIO-loaded SN can preoperatively be identified by magnetometer-guided ultrasound. This could allow it to be clipped prior to commencing neoadjuvant chemotherapy. Ultimately, magnetometer-guided biopsies of the SN could supersede surgical SNB.

DISCLOSURE The authors have no conflicts of interest to disclose.

OPEN ACCESS This article is distributed under the terms of the Creative Commons Attribution 4.0 International License (http://crea tivecommons.org/licenses/by/4.0/), which permits unrestricted use, distribution, and reproduction in any medium, provided you give appropriate credit to the original author(s) and the source, provide a link to the Creative Commons license, and indicate if changes were made.

\section{REFERENCES}

1. Karakatsanis A, Christiansen PM, Fischer L, Hedin C, Pistioli L, Sund M, et al. The Nordic SentiMag trial: a comparison of super paramagnetic iron oxide (SPIO) nanoparticles versus $\mathrm{Tc}(99)$ and patent blue in the detection of sentinel node (SN) in patients with breast cancer and a meta-analysis of earlier studies. Breast Cancer Res Treat 2016;157(2):281-94.

2. Karakatsanis A, Olofsson H, Stålberg P, et al. Simplifying logistics and avoiding the unnecessary in patients with breast cancer undergoing sentinel node biopsy. A prospective feasibility trial of the preoperative injection of super paramagnetic iron oxide nanoparticles. Scand J Surg 2018;107(2):130-37.

3. Wärnberg F, Stigberg E, Obondo C, Olofsson H, Abdsaleh S, Wärnberg M, Karakatsanis A. Long-term outcome after retroareolar versus peritumoral injection of superparamagnetic iron oxide nanoparticles (SPIO) for sentinel lymph node detection in breast cancer surgery. Ann Surg Oncol 2019;26:1247-53.

4. Karakatsanis A, Hersi AF, Pistiolis L, Olofsson Bagge R, Lykoudis PM, Eriksson S, Wärnberg F, SentiNot Trialists Group. Effect of preoperative injection of superparamagnetic iron oxide particles on rates of sentinel lymph node dissection in women undergoing surgery for ductal carcinoma in situ (SentiNot study). Br J Surg 2019;106(6):720-28.

5. Hersi AF, Eriksson S, Ramos J, Abdsaleh S, Wärnberg F, Karakatsanis A. A combined, totally magnetic technique with a magnetic marker for non-palpable tumour localization and superparamagnetic iron oxide nanoparticles for sentinel lymph node detection in breast cancer surgery. Eur J Surg Oncol 2018. http s://doi.org/10.1016/j.ejso.2018.10.064. [Epub ahead of print].

Publisher's Note Springer Nature remains neutral with regard to jurisdictional claims in published maps and institutional affiliations. 